\title{
Lo sagrado y la desacralización
}

\author{
Ivana Anton Mlinar \\ FACULTAD DE FILOSOFÍA Y LETRAS \\ UNIVERSIDAD NACIONAL DE CUYO \\ MENDOZA \\ mlinariv@yahoo.es
}

\section{INTRODUCCIÓN}

¿Podría hablarse de una sociedad desacralizada? Es frecuente escuchar esta expresión dentro del marco del debate acerca de las sociedades o mundo modernos. Aparece como un tema más en la extensa y variada lista que da sustento al decir actual sobre las incontables crisis que parecen agobiar todo tiempo presente. No es en absoluto menuda la tarea de adentrarse en el inconmensurable mar de lo sagrado. Sin embargo, por mucho o poco que alcancemos a comprender o, al menos, intentar aprehender, no será en vano sino, por el contrario, de grandes frutos para una experiencia que escapa a muchos, y no por inaccesible, sino porque la impronta de su objeto no es vivida del modo acorde a su ser, esto es, el de la experiencia unificadora de la interioridad. Sin embargo, por ser ineludible para el hombre su posicionamiento frente a lo sagrado, se presentará inevitablemente, aunque quizás enmascarado o huidizo; incluso donde se lo niega o se le responde con indiferencia. Pero, sin más prefacios, duc in altum!, adentrémonos ya en tan vasto mar.

\section{Lo SAgrado}

En las cercanías de una iglesia se celebra un acto solemne debido a su reciente restauración. Muchos que están fumando se ven sorprendidos ante la petición de alguien: se ruega no fumar, estamos en una iglesia. La misma prohibición tiene lugar en un sector dedicado a la memoria de soldados caídos. En Israel, a un grupo de extranjeros que cena en un restaurante se le solicita que no encienda sus cigarrillos, y no por ser un 
lugar cerrado, sino por ser viernes: el sábado judío ya había comenzado. Estas exigencias no tienen su fundamento en un peligro (como, por ejemplo, de posible incendio en una fábrica) o en la salud (en el caso de un hospital), etc. Hay aquí, más bien, la intención de salvaguardar y hacer visible una diferencia, una frontera que distingue un lugar, un tiempo, un objeto no corrientes, de otros irrelevantes o que, habitualmente, pasan inadvertidos. Y al traspaso del umbral corresponden actitudes distintas de las comunes.

Aunque las modalidades puedan variar, en todos los casos se trata de un algo que exige respeto, veneración, homenaje. Lo paradójico radica en el hecho de que, sin dejar de ser realidades del mundo natural, se produce la manifestación de algo completamente diferente, de otra cosa, a la que acompaña esencialmente el misterio.

Esta dignidad excepcional de lo sagrado que interrumpe la homogeneidad de espacios y tiempos, también se manifiesta en los significados originales de los términos que aluden a ello. Por ejemplo, en griego, ärıos (santo) se opone a kolvós (mediocre, común, vulgar) ${ }^{1}$. En latín, el verbo sancio, del que proviene el término sanctus, significa delimitar, hacer inviolable ${ }^{2}$. Para los antiguos romanos, sanctio era la delimitación de lugares sagrados y su correspondiente defensa de todo contacto profano. El término francés sacré corresponde, entre otras, a un orden de cosas separado, significado que también señala el Oxford Dictionary como una de las acepciones de sacred ${ }^{3}$. Y, si bien en alemán existen varios términos (sakral, heilig, geweiht) para designar esta realidad, a pesar de las diversas connotaciones, permanece aquel sentido de dignidad que sobresale entre un acontecer seriado, la que, en consecuencia, exige formas particulares de respeto. Recordemos, por ejemplo, a Kant: "La ley moral es santa (inviolable)" "4 que, aunque estemos en presencia de un significado completamente distinto de santo, con todo, está presente esa maiestas

1 Cf. Diccionario Griego-Español. Ed. por J. Pabón S. de Urbina, Vox, Barcelona 1995.

2 Cf. Diccionario Latino/Español-Español/Latino. Ed. por A. Blanquez Fraile, Sopena, Barcelona 1974.

3 J. Pieper, ¿Qué significa "sagrado"? Un intento de clarificación (Rialp, Madrid 1990) cap. I.

4 "Das moralische Gesetz ist heilig (unverletzlich)». I. KANT, Kritik der praktischen Vernunft, A 155. 
que hace de lo santo una realidad con consistencia, fuerte, significativa, que viene a romper con lo homogéneo; es algo inviolable, por lo tanto, delimitado.

Una de las definiciones de lo sagrado que da M. Eliade es la siguiente: aquello que se opone a lo profano ${ }^{5}$, considerando que ambos constituyen modalidades existenciales diversas de estar en el mundo. Y son diversas porque tanto el tiempo como el espacio se ven configurados en un modo propio.

Ahora bien, quien habla de algo santo o sagrado en cuanto opuesto a lo profano, seguramente se referirá a una cualidad o rasgo de una parte de este mundo, y no, por cierto, a Dios. Aunque solo a Dios puede llamarse santo de un modo absoluto, nadie lo designaría como sagrado, pues santo y sagrado quieren decir, más bien, que determinadas acciones, lugares y tiempos se ordenan a lo divino de una manera que cae fuera del ámbito de lo habitual. Etimológicamente, profano no entraña ninguna negativa; se trata de aquello que se encuentra delante (pro-) de lo santo (fanum), lo que está a las puertas de lo sagrado. Profano no es lo no-santo. En todo caso, si bien puede hablarse, por ejemplo, de que todo pan es santo (en cuanto creado por Dios o en cuanto que sustenta la vida) o de que todo suelo es sagrado, no supone esto discutir la existencia de un Pan santo y un espacio consagrado en sentido absoluto, por antonomasia. Es esa densa presencia de lo divino que no se encuentra en cualquier lugar o tiempo, y que hace comprensible la frontera que separa lo santo (en tal sentido) de lo profano. Por eso resulta cuestionable aquella tajante definición de Eliade, pues el ámbito de lo no-sagrado no puede entenderse como algo al margen o contrario a Dios. Parecería más acertado ver esta distinción en el seno de una totalidad que abarca ambos miembros, ya que, si no se diese ninguna solidaridad entre ambos, es decir, si el mundo que está ante el portal de lo sagrado no guarda relación o referencia alguna al mundo radicalmente heterogéneo de lo sacro; la misma distinción entre sagrado y profano carecería de sentido.

Sin embargo, en algunos comentarios parece admitir Eliade este necesario flujo entre los ámbitos o, al menos, la imposibilidad de la ausencia de la sacralidad. Afirma, por un lado, que para la experiencia profana el espacio es homogéneo, neutro, aunque, paradójicamente, siguen in-

5 M. Eliade, Lo sagrado y lo profano (Guadarrama, Madrid 1973) 18. 
terviniendo valores que recuerdan la no-homogeneidad que caracteriza la experiencia religiosa del mismo, lugares santos, únicos, que, para el hombre que opta por una vida profana, se cargan de otra realidad distinta de la que participa en su existencia cotidiana; tal es el caso del paisaje natal, un lugar propio de los primeros amores, etc. ${ }^{6}$.

\section{REFERENCIA NECESARIA A LA ACCION SAGRADA}

Si hablamos de tiempos, lugares y objetos sagrados es por su ordenación a una acción sagrada. Ella se destaca del acontecer cotidiano y no es algo que solo tiene lugar en un momento dado, sino que la acción sagrada se celebra. Y celebrar (celebrare) no es únicamente reverenciar, aplaudir o alabar (por celeber), sino que lleva implícita en latín la idea de frecuencia o repetición, como leemos en un diccionario: "frecuentar o visitar muchas veces un lugar o una persona" ". Una acción sagrada es una reactualización de un acontecimiento sagrado que se hace indefinidamente recuperable y que, a decir tanto de filósofos como de teólogos y santos, no "transcurre", y "deberían pararse los relojes" cuando ella tiene lugar.

Es necesario, sin embargo, precisar una importante diferencia entre el cristianismo y las demás religiones, para las que esta recuperación de los hechos está relacionada con un Tiempo originario, mítico, anterior a cualquier realidad, mientras que, para el cristianismo, la acción litúrgica renueva un tiempo, una acción, una realidad con historicidad en la persona de Cristo, el Hijo de Dios ${ }^{10}$.

La experiencia de la acción sagrada (y, en consecuencia, lo sagrado en general) es la experiencia de la verdadera realidad. En tal sentido y, recurriendo una vez más a los aportes de estudios etimológicos, podemos agregar otros descubrimientos: según comenta J. Ries ${ }^{11}$, la palabra

6 Cf. M. Eliade, Lo sagrado y lo profano, 27-28.

7 Cf. Diccionario Latino/Español-Español/Latino. Voz: celebro.

8 Cf. M. Eliade, Lo sagrado y lo profano, cap. II.

9 Cf. J. Escrivá de Balaguer, Forja 436: «Es tanto el Amor de Dios por sus criaturas, y habría de ser tanta nuestra correspondencia que, al decir la Santa Misa, deberían pararse los relojes».

10 Cf. M. Eliade, Lo sagrado y lo profano, cap. II.

11 Cf. J. Ries, Lo sagrado en la historia de la Humanidad cit. en J. M. Mardones, Para comprender las nuevas formas de la religión (Verbo Divino, Navarra, 1994) 20-21. 
sakros, que aparecía en un texto hallado en un lugar conocido como la tumba de Rómulo, tiene relación con el germánico sakan, el hitita saklai, el griego ärıos, y da un rodeo por el término latino sancire. Su significado es hacer sak-, lo que quiere decir: conferir validez, realidad. Se trata de "hacer que una cosa llegue a ser real". Por lo tanto, el radical sak-, que se encuentra en la base de las palabras indoeuropeas que expresan lo sagrado, toca el fundamento de lo real. Y, a partir de esto, la deducción de que lo sagrado significa lo que es real, lo que existe. Nos aproximamos así a la noción de presencia intensa, de saturación de ser, de realidad por excelencia o existencia cuasi absoluta que encontramos en la teoría de M. Eliade ${ }^{12}$.

\section{El Símbolo}

Detrás de la experiencia de lo sagrado está la búsqueda y desvelamiento de la realidad en su hondura más radical. Pero, ¿cómo habla o se revela ese mundo para que tengamos acceso a él? Constatamos que no tenemos acceso directo a él, no hay una experiencia inmediata del mismo. Con palabras de van der Leeuw, decimos que lo santo tiene que suceder, tiene que volverse espacial, temporal. Y la mediación de lo eterno en lo temporal es el simbolo, esa abertura por la que se cuelan en nuestro mundo presente las fuentes profundas de la vida. Aquel suceder no es el mero acontecer, aunque todo acontecer puede ser un suceder de lo santo, caso en el que hablamos de símbolo. Es "el encuentro de la posibilidad y lo dado, del acontecer y el suceder", es la participación "de lo santo en su figura actual. Entre lo santo y su figura existe la comunidad esencial"13. El acontecer está conectado esencialmente con la santidad, es su imagen y adquiere su valor en ella. Lo santo es lo que existe de inmediato, y lo profano tiene valor y consistencia por el hecho de que puede estar en posición de simbolizar lo sagrado. De allí la estrecha comunidad, más que tajante oposición, entre lo sagrado y lo profano, a la que aludimos antes.

12 “[...] para los «primitivos» como para el hombre de todas las sociedades premodernas, lo sagrado equivale a la potencia y, en definitiva, a la realidad por excelencia. Lo sagrado está saturado de ser. [...] Es, pues, natural que el hombre religioso desee profundamente ser, participar en la realidad, saturarse de poder”. M. Eliade, Lo sagrado y lo profano, 20.

13 Cf. G. van der Leeuw, Fenomenología de la religión (Fondo de Cultura Económica, México 1964) $\$ 65$. 
El símbolo, en definitiva, evoca, es un lenguaje de la excedencia, señala otra mitad, pues hay en él firmes tanto la idea de separación como de reunión, de manifestación como de ocultamiento: revela velando y vela revelando. Contrariamente al pensamiento científico, el símbolo "no procede por reducción de lo múltiple a lo uno, sino por explosión de lo uno hacia lo múltiple, a fin de percibir mejor, en un segundo momento, la unidad de lo múltiple"14; es más implicación que explicación ${ }^{15}$. Y aquí aparece otro de los elementos de la acción simbólica: el elemento del exceso, de la ausencia de cálculo, de lo "superfluo": encender un cirio, pero no para iluminar; el toque de campanas en una catedral sin el fin de señalar una hora, sino como muestra de júbilo, etc.

La magnificencia que suele tener la acción cultual o sagrada que, si bien no se identifica necesariamente con el lujo material, tampoco lo excluye, es la natural manifestación de la riqueza que consiste en la experiencia de la real presencia de Dios. El canto no puede ser económico y ser canto a la vez. A la imagen sensible, a la música, en general: a lo que llamamos arte, a lo bello, le es común el poder expresar lo que la razón percibe con dificultad; y, en el caso de las cosas divinas -como dice Santo Tomás-, por su exceso de verdad, hay la necesidad de recurrir a las imágenes sensibles ${ }^{16}$.

Un concepto desacralizado de festejo propugna una humanización de la acción simbólica sagrada, como una integración de la misma en el transcurrir sin fronteras del día. Es evidente que la legitimidad de todo símbolo no se asumirá, del mismo modo que será una violencia insoportable toda forma acuñada, si es discutida la verdad bimembre del principio anima forma corporis, pues es también el fundamento de toda formación litúrgica, en una palabra, de toda sacralidad; y esto porque "el culto es doble: interno y externo. Pues estando el hombre compuesto de alma y cuerpo, debe aplicar ambos a honrar a Dios, de manera que el

14 J. Chevalier, Diccionario de los simbolos cit. en J. M. Mardones, Para comprender las nuevas formas de la religión, 23.

15 Cf. Tomás de Aquino, Summa Theologiae, I-II, q. 101, a. 2, ad. 1. "[...] diremos que las cosas divinas no deben ser reveladas a los hombres sino según su capacidad; [...]. Y por esta razón fue más útil se diese a conocer al rudo pueblo los misterios divinos bajo cierto velo de figuras, a fin de que así al menos tuvieran de ellos un conocimiento implícito, y dieran por estas figuras el honor debido a Dios".

16 Cf. S. Th., I-II, q. 101, a. 2, ad. 2. 
alma le reverencie por el culto interior y el cuerpo por el exterior" ${ }^{17}$. De allí la adusta ${ }^{18}$ forma que reviste el lenguaje sagrado, tanto en sus gestos como en los signos y palabras. La razón no hay que buscarla meramente en el posible carácter comunitario de una acción sagrada, sino que, más bien, se pretende evitar lo singular y subjetivo, del mismo modo que un poema acabado se sustrae a cualquier cambio caprichoso. Se hace una invitación a ir más allá de los límites del reducido yo y entrar en la objetividad encarnada de las grandes formas de la Liturgia.

\section{SACRAMENTALIDAD y DESACRALIZACión}

Símbolos, formas, encarnación. La objeción moderna no se refiere tanto al significado de una acción sagrada, sino, más bien, a su contenido. Se duda de la presencia real de lo divino, se niega la sacramentalidad. No hay apertura al misterio. $\mathrm{Y}$, es que se trata de otra vivencia, de otro modo de hacerse presente la trascendencia que no es el de la mera representación por la sensibilidad. Dice San Juan Crisóstomo que "hay misterio cuando consideramos las cosas como otras distintas de aquellas que vemos" ${ }^{19}$. La negación de la sacramentalidad es la raíz de toda desacralización; y el convencimiento de que las acciones sagradas son una representación puramente humana en la que no sucede absolutamente nada, es evadir una realidad que se encuentra toda en todas (las acciones sagradas), no por necesidad, sino por misterio ${ }^{20}$.

Sin embargo, es significativo que, aunque misteriosa, puede hablarse de la modalidad racional de esta realidad para la conciencia, por su rasgo de evidente. Es Husserl quien reconoce esta presencia en la conciencia del ser humano, pero con características diversas de la inmanencia de lo vivido en la misma conciencia. Dice: "[...] deben estar en la corriente de

17 S. Th., I-II, q. 101, a. 2.

18 Es llamativo el modo en que este término puede calificar las formas de lo sagrado. Su peculiaridad radica en su doble significación que tan acertadamente expresa esta realidad. Su sentido figurativo es: austero, severo, melancólico. En cuanto participio pasado antiguo de adurir significa: ardiente, que produce excesivo calor, que abrasa.

19 "Il y a mystère, quand nous considérons des choses autres que celles que nous voyons [...]”. Dictionnaire de Théologie Catholique, Vacant, Mangenot, Amann, (Librairie Letouzey, Paris 1939) tome quatorzième, première partie, voz: sacrements.

20 "[...] où Dieu se trouve tout en tous, non par nécessité, mais par sacrement (mystère)". Saint Hilaire. Dictionnaire de Théologie Catholique, voz: sacrements. 
la conciencia y en la serie infinita, otros modos de anunciarse la trascendencia además de aquel que da lugar a la constitución de la realidad física como unidad de apercepciones concordantes" ${ }^{21}$. Con otras palabras dice Lactancio (haciendo uso de diversos sentidos del término 'sacramentum', no fijado aún en su significado actual): "es la única verdadera doctrina (sacramentum veritatis) que no puede ser conocida más que por revelación (mysterium sacramenti) y que funda apreciaciones desconocidas por la sola razón humana, sobre la naturaleza de Dios (sacramentum Dei), sobre las relaciones del Hijo con el Padre (sacramentum nativitatis suae), sobre los destinos del hombre (sacramentum hominis) y del mundo entero (sacramentum mundi): doctrina misteriosa, por ser revelada, y sagrada, por provenir de Dios"22.

Este otro modo de anunciarse la trascendencia es la revelación, para la que figurativamente se recurre al oído como medio para su acogimiento, ya que "visus, tactus, gustus in te fallitur, / sed auditu solo tuto creditur; $/[\ldots] " 23$. Se da esta vivencia como presencia, luego como encuentro y finalmente como reunión ${ }^{24}$. Sin embargo, aunque revelación, no es mostración. Solo lo que está esencialmente escondido, que no es accesible por otro camino del conocimiento, se comunica por revelación. Aunque se revela, no deja de estar oculto; incluso se revela como oculto. No puede entenderse la revelación en su esencia, de lo contrario, no sería tal. Sin embargo, es condición de todo entendimiento.

21 E. Husserl, Hua III/1, 109 [Ideas I, nota al \$ 51]. También comentado en: A. Alles Bello, Culturas y religiones. Una lectura fenomenológica, Città Nuova, Roma 1997, trad. por H. Padrón.

22 '“...] c'est la seule vraie doctrine (sacramentum veritatis), qui ne peut être connue que par révélation (mysterium sacramenti) et qui ouvre des aperçus inconnus de la seule raison humaine, sur la nature de Dieu (sacramentum Dei), sur les rapports du Fils avec le Père (sacramentum nativitatis suae), sur les destinées de l'homme (sacramentum hominis) et du monde entier (sacramentum mundi): doctrine mystérieuse, parce que révélée, et sacrée, parce que venant de Dieu”. Dictionnaire de Théologie Catholique, voz: sacrements.

23 Tomás de Aquino. Himno Adoro te devote. Fragmento.

24 Decía J. Escrivá de Balaguer en el punto 382 de Camino: "Al regalarte aquella Historia de Jesús, puse como dedicatoria: «Que busques a Cristo: Que encuentres a Cristo: Que ames a Cristo». -Son tres etapas clarísimas. ¿Has intentado, por lo menos, vivir la primera?". 


\section{EL AMOR: ÚNICO FUNDAMENTO}

Si este acogimiento (fe) de lo revelado viene por el oído, debe hablarse al que escucha. El hablar y el proclamar no se remiten a sí mismos sino a algo distinto, a otra realidad. Debe comprenderse el carácter derivado y subordinado del lenguaje y, por ende, de la celebración cultual. Lo que se da en él, lo que acontece por él es la presencialización, el hacerse presente de algo ya sucedido. La realidad de este cumplimiento encuentra su razón solo en el amor. "En el amor se encuentran la línea que asciende del hombre a Dios y la que desciende de Dios al hombre. El símbolo del amor es la cruz" ${ }^{25}$. Cristo reúne en sí las dos direcciones. Él es el amante: el hombre que ama a Dios y Dios que ama a los hombres. De allí que, no solo el amor, sino el ser amado es lo principal y grandioso. La caridad, la $a \dot{\gamma} \dot{a} \pi \eta \eta$ cristiana es entrega a aquel que se ha entregado, no es impulso o impotencia sino gracia, pura gratitud. De hecho, su significado fundamental es recibir, acoger, aceptar. Es una disposición que responde al acto de Dios. Ni siquiera es en primer término un dar, sino un dejarse dar. "En eso está el amor (á rá $\pi \eta)$, no en que nosotros hayamos amado a Dios, sino en que Él nos amó y envió a su Hijo, víctima expiatoria de nuestros pecados" 26 . El amor humano solo existe como respuesta. $\mathrm{Ni}$ el amor a Dios ni el amor a otros hombres es propiedad de la criatura, sino don, regalo de Padre a hijo. "Nosotros amamos porque Él nos amó primero" 27 . Solo la incondicionalidad y predilección (prae-: antes, dilectio: amor, dilección) del Amor hace posible nuestra correspondencia.

Ahora bien, quien no pueda aceptar como verdadero suceso el acontecimiento original de la Encarnación, no solo en el tiempo sino también ontológicamente, tampoco vivirá la sacramentalidad. Pero aquel acontecimiento original que constituye el centro de la historia humana, no solo es algo difícil de entender, sino algo enteramente increíble si no tuviera la garantía de una palabra divina, de la Revelación en sentido estricto. Se trata de algo sencillamente imposible (como se ha querido considerar) si no supiéramos secretamente que siempre nos parece imprevisible e increíble lo absolutamente perfecto, pleno y acabado; la verdad de que Dios se hace hombre en Cristo en un acto de entrega que se puede fe-

\footnotetext{
25 G. Van der Leeuw, Fenomenología de la religión, p. 622.

261 Juan 4, 10.

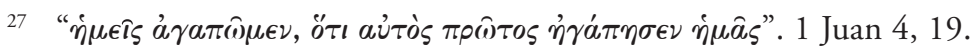


char en el tiempo, que ese Dios se dejó dar muerte por los hombres, por su propio pueblo, con el fin de que pudiéramos participar de la vida de Dios. Y, así, dice Santo Tomás que "el alma unida con el cuerpo es más semejante a Dios que la que está separada de él, porque aquella posee su propia naturaleza de una manera más perfecta" ${ }^{28}$, al contrario de lo que podría afirmarse del alma luego de la muerte, por ser puro espíritu, como Dios.

Nunca entenderemos por qué tuvo que ser necesario un sacrificio tan cruel en la cruz, aunque, por otro lado, no resulta ajeno a la experiencia íntima de nuestro corazón el hecho de que nadie tiene mayor amor que quien da la vida por la persona que ama. Ese extremo, ese "límite" insuperable es el que se expresa en los atributos de omnipresencia, omnisciencia, omnipotencia, etc., y que son solo noticia del amor, que es el que verdadera y completamente se experimenta como algo último. Último por término ( $\pi \dot{e} \rho a \varsigma$ ), "lo primero fuera de lo cual no es posible tomar nada..., y lo primero dentro de lo cual está todo [...], aquello desde lo que se comienza y aquello a lo que se dirige y la causa final, y la substancia de cada cosa y la esencia de cada cosa; [...]"29. El apóstol Pablo exulta diciendo: "Si yo hablara todas las lenguas de los hombres y de los ángeles, y me faltara el amor, no sería más que bronce que resuena y campana que toca. Si tuviera profecía y entendiera todos los misterios y toda ciencia, y tuviera tanta fe como para trasladar los montes, pero me faltara el amor, nada soy. [...] El amor nunca pasará. [...] Ahora tenemos la fe, la esperanza y el amor, los tres: pero el mayor de ellos es el amor" ${ }^{\prime 30}$.

Podemos acceder a este algo último, vivencia límite, realidad esencialmente misteriosa, porque es revelada. Y, así, comprendemos que, en realidad, somos comprendidos, que el último fundamento de la comprensión no se encuentra en quien comprende, sino en otra cosa que lo comprende a él, desde más allá del límite. Toda comprensión radical cesa de serlo antes de alcanzar el fondo y se reconoce como un ser-comprendida. Nos comprendemos en Dios. Porque toda comprensión descansa en el amor que se entrega. De lo contrario, no solo cualquier discurso

28 "Anima corpori unita plus assimilatur Deo quam a corpore separata, quia perfectius habet suam naturam". Quaest. disp. de potentia Dei 5, 10 ad 5 cit. en: J. PIEper, Muerte e inmortalidad (Herder, Barcelona 1970) 62.

29 Aristóteles, Metafísica V, 17 [1022 a 4 - 14], voz: tépas (término).

301 Corintios 13. 
de lo que se manifiesta en la religión sería imposible, sino también todo enunciado sobre lo que se muestra en general. Porque solo quien ama, acoge; a quien no ama no se le muestra nada. El amor abre paso a la evidencia, se hace disponibilidad a la revelación ${ }^{31}$.

\section{Conclusión}

Como se anticipó, en la sociedad moderna se han hecho presentes manifestaciones pálidas, encubiertas, fragmentadas y rotas de lo sagrado. Para intentar comprender este fenómeno de desacralización, comenzamos por indagar la esencia de lo sagrado. Nuestro análisis intentó poner de manifiesto que de ese sentido de delimitación e inviolabilidad presente en su radical etimológico, no se desprende su oposición tajante con lo profano, sino que, más bien, debía entenderse un acento de realidad, una primacía ontológica, de tal manera que lo profano no podía comprenderse como lo no-santo sino como lo que está a las puertas de lo santo, lo que es capaz de santidad.

Ahora bien, la densidad ontológica propia de lo sagrado se mostró deudora de la acción sagrada, por la que lo santo sucede. Es aquí donde tiene lugar el quiebre en el que se origina toda vivencia desacralizada: personas, tiempos y lugares pueden cargarse de una densidad de sentido que las posicione de manera preeminente frente al transcurrir homogéneo de lo cotidiano; y, así, vemos transitar "lo sagrado" por nuestras calles: horóscopos, astrología, esoterismo barato llenan páginas de revistas, libros y hasta emisiones radiales y televisivas. Su relativo éxito indica que lo sagrado no ha muerto en el interés de nuestros contemporáneos. Pugna por adquirir dignidad y extenderse, aunque lo haga por esos laberintos de lo oscuro, adivinatorio, sincrético y marginal. Frecuentemente toca lo cristiano buscando, contra las expresiones institucionales, sacar a relucir caras o facetas desconocidas de Jesús, o bien las acciones, relaciones o hechos ocultos de la Iglesia. Surge así un Cristo marginal, inventado, con rasgos apócrifos y poca seriedad histórica, pero con gran atractivo para los sedientos de novedad y de contrapesar el racionalismo intelectual y el hieratismo institucional con un poco más de fantasía, cercanía y hasta milagrerismo. Esta trivialización de lo sagrado se da como un in-

\footnotetext{
31 Cf. G. VAN Der Leeuw, Fenomenología de la religión, $\$ 111$.
} 
tento curioso de recuperar el olor y sabor del incienso sagrado en medio de la ciudad secular.

La diferencia esencial con el cristianismo radica en el reconocimiento de un acontecimiento histórico y ontológico: la encarnación de Dios. Lo sagrado no es una mera saturación de sentido, según se describiría una vivencia desacralizada, sino que la acción sagrada celebra (reactualiza ese acontecimiento) y confiere realidad: tiene lugar la sacramentalidad. Así se comprende también la cercanía y potencialidad de lo profano respecto de lo sagrado.

En toda manifestación, incluso desfigurada, de lo sagrado se puede captar esa irrefrenable inclinación del hombre hacia su plenificación. Y es que el hombre fue creado no solo a imagen y semejanza de Dios, sino en amistad con Él. La búsqueda de esta amistad es su verdadero sosiego. Pero desde la transformación acontecida con la hierofanía suprema, que es la encarnación de Dios en Jesucristo, la historia misma se ha vuelto teofanía. Hasta este momento era fácil distinguir lo sagrado de lo profano; ahora hay que esforzarse continuamente por develar en la masa de los acontecimientos históricos la salvación que los atraviesa. Una labor de discernimiento permanente que hace de la vida cristiana una tensión continua. Porque el hombre ya no puede entregarse ni a la evasión ni a la pura aceptación, sin más. La encarnación señala la más alta sacralización. $Y$ es esta una realidad a la que el hombre debe consagrar su fidelidad. 
Resumen: La dignidad excepcional de lo sagrado que interrumpe la homogeneidad de espacios y tiempos resulta un suceso ineludible para todo hombre, pues en esta experiencia se halla la búsqueda y desvelamiento de la realidad en su hondura más radical. Por medio de la acción sagrada lo santo sucede. En tal sentido, lo santo es lo que existe de inmediato, y lo profano, lo que asume la posición o capacidad de simbolizar lo sagrado, dándose así una estrecha comunidad entre ambos. La objeción moderna duda de la presencia real de lo divino en la acción sagrada, y esta negación de la sacramentalidad es la raíz de toda desacralización. La aceptación del acontecimiento original de la Encarnación - no solo en el tiempo sino también ontológicamente- es el fundamento que permite vivir la sacramentalidad.

Palabras clave: Sagrado, desacralización, acción sagrada, símbolo, sacramentalidad

Abstract: The exceptional dignity of the sacred that interrupts the homogeneity of spaces and times becomes an unavoidable event for every person, because in this experience has its place the quest for and the unfolding of reality in its most radical depth. Via the sacred action the sacred happens. Thus the sacred is what exists immediately, and the profane what assumes the position or capacity for symbolizing the sacred, taking place a close community between both. The modern objection doubts about the real presence of the divine in the sacred action, and this negation of sacramentality is the root of all disacralization

Keywords: Sacred, disacralization, sacred action, symbol, sacramentality. 
